\title{
Effects of Compaction Pressure and Particle Shape on the Porosity and Compression Mechanical Properties of Sintered Ti6Al4V Powder Compacts for Hard Tissue Implantation
}

\author{
Mustafa Güden, ${ }^{1,2,3}$ Emrah Çelik, ${ }^{3}$ Alpay Hızal, ${ }^{1,4}$ Mustafa Altındiş, ${ }^{3}$ Sinan Çetiner ${ }^{4}$ \\ ${ }^{1}$ Department of Mechanical Engineering, Izmir Institute of Technology, Gulbahce Koyu, Urla, Izmir, Turkey \\ ${ }^{2}$ Center for Materials Research, Izmir Institute of Technology, Gulbahce Koyu, Urla, Izmir, Turkey \\ ${ }^{3}$ Materials Science and Engineering Program, Izmir Institute of Technology, Gulbahce Koyu, Urla, Izmir, Turkey \\ ${ }^{4}$ Hipokrat A.Ş., 407/6 Sok., No:10, Pınarbaşı Izmir, Turkey
}

Received 6 December 2006; revised 11 July 2007; accepted 26 July 2007

Published online 12 December 2007 in Wiley InterScience (www.interscience.wiley.com). DOI: 10.1002/jbm.b.30978

\begin{abstract}
Sintered Ti6Al4V powder compacts potentially to be used in implant applications were prepared using commercially available spherical and angular powders (100-200 $\mu \mathrm{m})$ within the porosity range of $34-54 \%$. Cylindrical green powder compacts were cold compacted at various pressures and then sintered at $1200^{\circ} \mathrm{C}$ for $2 \mathrm{~h}$. The final percent porosity and mean pore sizes were determined as functions of the applied compaction pressure and powder type. The mechanical properties were investigated through compression testing. Results have shown that yield strength of the powder compacts of 40-42\% porosity was comparable with that of human cortical bone. As compared with previously investigated Ti powder compacts, Ti6Al4V powder compacts showed higher strength at similar porosity range. Microscopic observations on the failed compact samples revealed that failure occurred primarily by the separation of interparticle bond regions in the planes $45^{\circ}$ to the loading axis. (C) 2007 Wiley Periodicals, Inc. J Biomed Mater Res Part B: Appl Biomater 85B: 547-555, 2008
\end{abstract}

Keywords: titanium (alloys); mechanical properties; porous; compression

\section{INTRODUCTION}

Porous implant components based on biocompatible metallic materials (e.g., Ti and Ti6Al4V) are expected to provide better interaction with bone. This is partly because of higher degree of bone growth into porous surfaces and higher degree of body fluid transport through three-dimensional interconnected array of pores, ${ }^{1}$ leading to improved implant fixation. Furthermore, relatively low elastic modulus of porous metals as compared with those of bulk metals is expected to reduce the extent of stress shielding, which causes well-known implant loosening, and hence to prolong implant life-time. ${ }^{2}$

Open cell Ti foams potentially to be used in biomedical applications were previously prepared using a powder metallurgical process known as space holder method. ${ }^{3-5}$ The method allows a direct near net-shape fabrication of foamed implant components having elastic modulus compa-

Correspondence to: M. Güden (e-mail: mustafaguden@iyte.edu.tr)

Contract grant sponsor: Technology Development Foundation of Turkey (TTGV); contract grant number: TTGV-102/T13

(C) 2007 Wiley Periodicals, Inc. rable with that of natural bone and with a relatively homogeneous pore structure and a high level of porosity (60$80 \%){ }^{3-5}$ By reducing the "elastic-mismatch" as well as "strength-mismatch" between metallic implant and bone, it is expected to have better performance of implant-bone compound which can be called as "isoelastic multimaterial system". For this purpose numbers of innovative investigations have been undertaken world-wide. Oh et al. ${ }^{6}$ reported that the modulus and bending strength of sintered Ti powder compacts were also comparable with those of human bone. It was further shown by the same authors that the porosity level of sintered $\mathrm{Ti}$ compacts suitable for the bone replacement was around 30\%, which was in accordance with the proposed optimal porosity for the ingrowths of new-bone tissues. The compressive yield strength of sintered Ti compacts was however found to be lower than that of the human cortical bone because of the relatively low yield strength of Ti powder. ${ }^{6}$ One way of increasing the yield strength of powder compacts is to use stronger biocompatible $\mathrm{Ti}$ alloy powders. This experimental study is therefore conducted to produce stronger sintered powder compacts that can potentially be used in biomedical applications (load carrying implants) including human cortical 


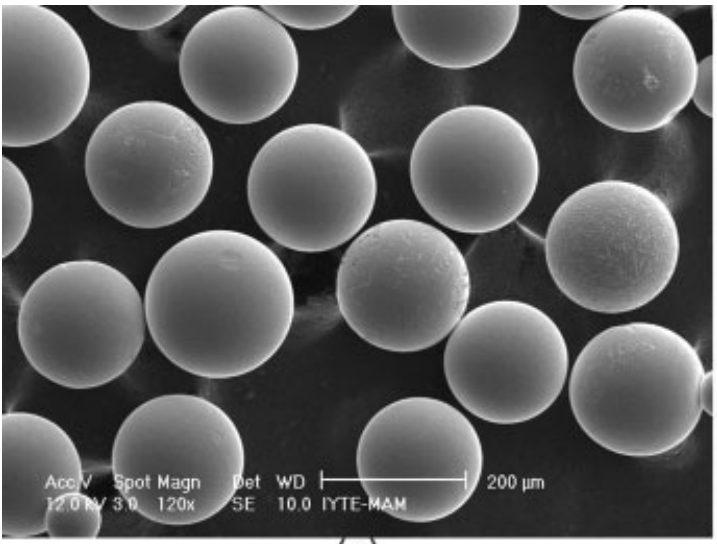

(a)

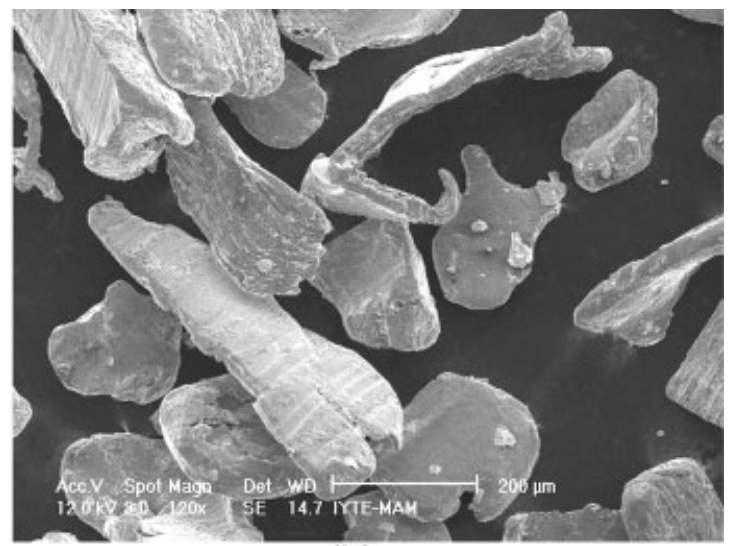

(b)

Figure 1. SEM images of the sieved (a) Powder A and (b) Powder B.

bone replacement. The experimental work presented focused so far on (a) the preparation of Ti6Al4V (Ti64) compacts with various porosity and pore sizes and (b) the determination of compression mechanical properties of compacts as function of porosity. The final aim of the work was the optimization of the process and properties to satisfy the biomechanical design requirements for certain implants.

\section{MATERIALS AND TESTING METHODS}

The sintered powder compacts were prepared using two different commercial Ti64 alloy powders; atomized spherical particles (Powder A) and angular (irregular) particles (Powder B). Powder A and B were manufactured by Phelly Materials and by Solea-Sas Company, respectively. The chemical composition of Powder A and B complied with ASTM 1580-1 standard. ${ }^{7}$ The particle size of Powder A ranged between 29 and $250 \mu \mathrm{m}$ with a mean particle size of $140 \mu \mathrm{m}$. The particle sizes of Powder B ranged between 40 and $400 \mu \mathrm{m}$ with a mean particle size of $170 \mu \mathrm{m}$. The powders were sieved in the particle size range of 100-200 $\mu \mathrm{m}$ to use similar particle size range in both powders. The mean particle sizes were determined microscopically as 157 and $160 \mu \mathrm{m}$ for Powder A and Powder B, respectively. As-received Powder A particles are spherical and have nearly uniform particle size [Figure 1(a)] while Powder B particles are in the form of oblate [Figure 1(b)]. The particle size in Powder B was determined by averaging the long and short axis lengths of the particles.

Green powder compacts, $16 \mathrm{~mm}$ in diameter, were compacted at room temperature inside a cylindrical steel die. It was found that without using a binder, Powder A could not be shaped until about the pressures of $400 \mathrm{MPa}$; therefore, polyvinyl alcohol solution ( $5-10 \%$ by volume) was used as the binding material. Compaction pressures chosen for Powder A and B were 200, 300, 400, and $500 \mathrm{MPa}$ and 50, $100,200,300$, and $400 \mathrm{MPa}$, respectively. At the compac- tion pressures lower than $200 \mathrm{MPa}$, Powder A green compacts could not be shaped and the compaction pressures higher than $400 \mathrm{MPa}$ formed lateral cracks on Powder B compacts. The sintering of green compacts was performed in a tightly enclosed horizontal tube furnace under the high purity $(99.998 \%) \mathrm{Ar}$ atmosphere at $1200^{\circ} \mathrm{C}$ for $2 \mathrm{~h}$. The sintering temperature and time chosen were based on the previous sintering studies on $\mathrm{Ti}$ foam and powder compacts. $^{3-6}$ For comparison purposes, relatively dense $(90 \%)$ Ti64 samples were prepared using 40-75 $\mu \mathrm{m}$ size particles (Powder B). These samples were compacted at $1000 \mathrm{MPa}$ and sintered at $1350^{\circ} \mathrm{C}$ for $2 \mathrm{~h}$. The compacts were inserted into the furnace at room temperature inside an enclosed $\mathrm{Ti}$ box on a graphite plate which prevented the bonding between $\mathrm{Ti}$ box and compacts. The compacts were heated and cooled in the furnace with a rate of $5^{\circ} \mathrm{C}$ min under continuous flow of Ar. In the heating cycle, the compacts were kept at $450^{\circ} \mathrm{C}$ for $1 / 2 \mathrm{~h}$ to allow the burning of the binder completely. The diameters of the compacts were measured following the sintering and found to be 15.50 $\mathrm{mm} \pm 2 \mathrm{~mm}$, corresponding to a sintering shrinkage of nearly $3 \%$.

Initial quasi-static compression tests were conducted on the sintered compact samples compacted at the same pressure but with different length/diameter $(l / d)$ ratios, $\sim 0.65$ and $\sim 1.5(15.50 \mathrm{~mm} \pm 2 \mathrm{~mm}$ in diameter $)$. These samples were tested in order to determine the $l / d$ ratio dependent compression properties of the compacts. Because the removal of relatively long green powder compacts from the steel die in compaction and subsequent handling before the sintering are relatively difficult, quasi-static compression properties of the sintered compacts were determined on the nonstandard samples with $l / d$ ratio of $0.65(15.50 \mathrm{~mm} \pm 2$ $\mathrm{mm}$ in diameter and $10 \mathrm{~mm} \pm 0.5 \mathrm{~mm}$ in length). Compression tests were conducted using a displacement controlled SHIMADZU AG-I universal tension-compression test machine. Tests were performed at a cross-head speed of $2 \mathrm{~mm} \mathrm{m^{-1 }}$ corresponding to a strain rate of $2 \times 10^{-3}$ $\mathrm{s}^{-1}$. During compression test, the tests plates and samples 


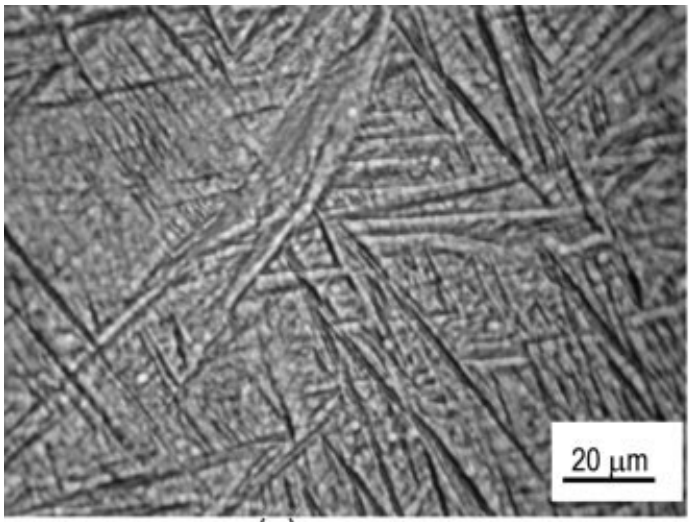

(a)

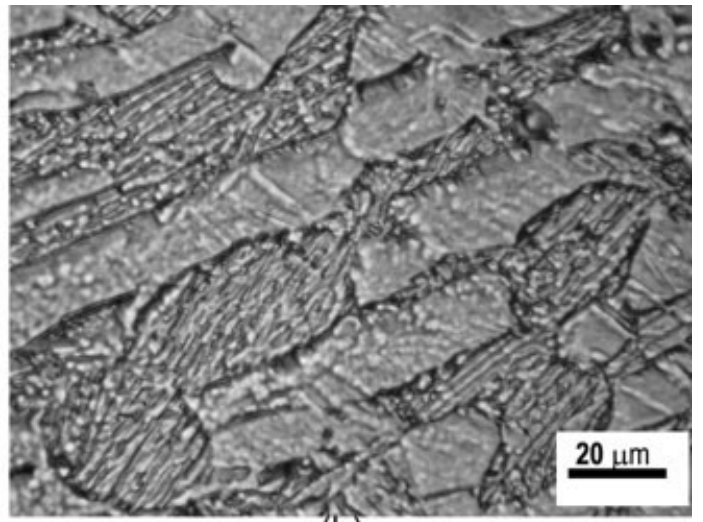

(b)

Figure 2. Optical micrographs of the microstructure of as-received (a) Powder A (martensitic $\alpha$ ) and (b) Powder B (bimodal).

surfaces were lubricated to reduce the friction between sample and test plates. At least three tests were conducted for each set of sintered powder compact samples.

Microscopic analysis was performed on the vacuum epoxy-mounted as-received powder and untested and tested compact samples using a Nikon Eclipse L150 optical microscope, a Philips XL30-SFEG scanning electron microscope (SEM) with an Energy Dispersive X-ray (EDX) analyzer, and a Nanoscope-IV Atomic Force Microscope (AFM) in tapping mode. The polished cross-sections of samples were etched with Kroll's reagent $\left(3 \mathrm{~cm}^{3}\right.$ of $\mathrm{HF}$ and $6 \mathrm{~cm}^{3}$ of $\mathrm{HNO}_{3}$ in $100 \mathrm{~mL}$ of $\mathrm{H}_{2} \mathrm{O}$ ). The percent porosities of sintered compacts were measured by the Archimedes' method after coating the surfaces of the compacts with paraffin. ${ }^{8}$ The open and closed porosities of compacts were calculated by the differences between dry

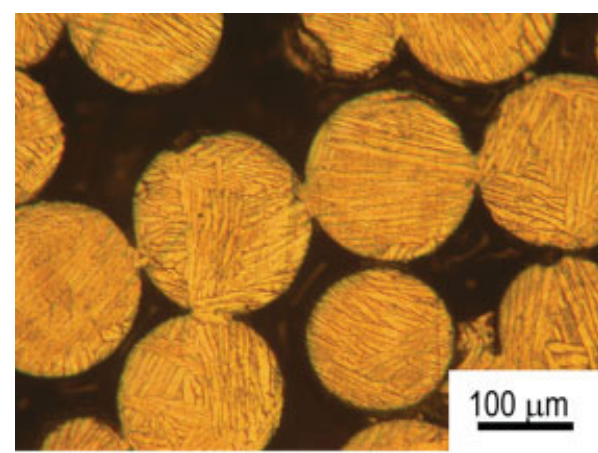

(a)

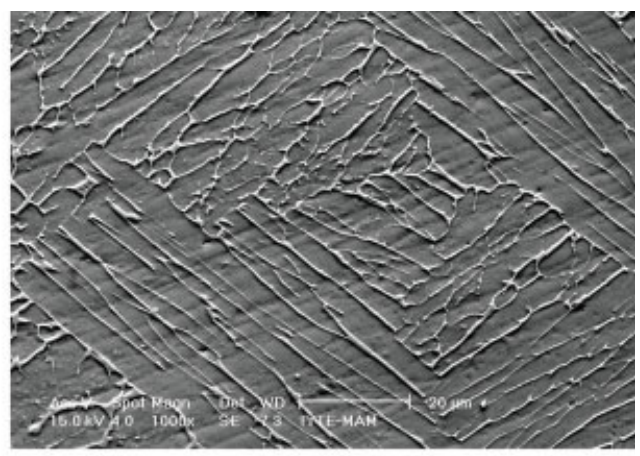

(b)

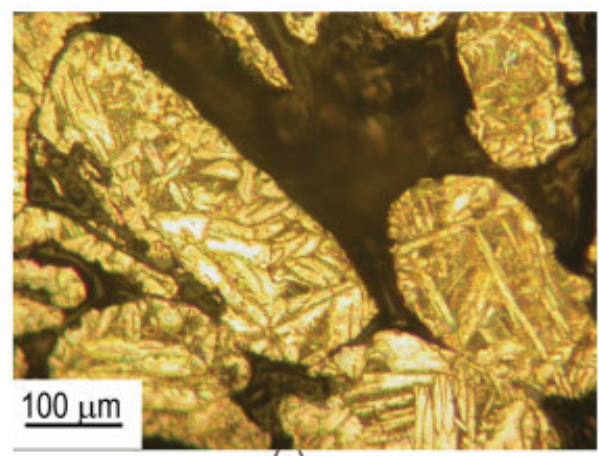

(c)

Figure 3. Micrographs showing (a) microstructure of Powder A compact particles compacted at $400 \mathrm{MPa}$, (b) SEM view of Widmanstätten structure of the Powder A compact and (c) microstructure of Powder $\mathrm{B}$ compact particles compacted at $400 \mathrm{MPa}$. [Color figure can be viewed in the online issue, which is available at www.interscience.wiley.com.] 
TABLE I. Compaction Pressure, Percent Porosity, and Mean Pore Size of the Sintered Compacts

\begin{tabular}{ccccc}
\hline & \multicolumn{2}{c}{ Powder A } & \multicolumn{2}{c}{ Powder B } \\
\cline { 2 - 5 } Compaction & $\begin{array}{c}\text { Porosity } \\
(\%)\end{array}$ & $\begin{array}{c}\text { Mean Pore } \\
\text { Size }(\mu \mathrm{m})\end{array}$ & $\begin{array}{c}\text { Porosity } \\
(\%)\end{array}$ \\
\hline Pressure (MPa) & - & & 54 & 98 \\
Size $(\mu \mathrm{m})$
\end{tabular}

${ }^{a}$ powder size less than $75 \mu \mathrm{m}$, sintered at $1350^{\circ} \mathrm{C}$.

and wet weights (boiling in water). Mean pore sizes of the compacts were calculated applying the linear intercept method on the images of the polished cross-sections of the compacts. At least five random lines were drawn onto the cross-section images of the powder compacts and then pore sizes intercepting with the random lines were measured.

\section{RESULTS}

The microstructure of as-received Powder A [Figure 2(a)] consists of acicular needle-like alpha $(\alpha)$ which is known as martensitic $\alpha .{ }^{9}$ This type of microstructure can form as a result of quenching after heat treatment above the beta $(\beta)$ transition temperature $\left(1050^{\circ} \mathrm{C}\right)$. The microstructure of angular Powder B is bimodal [Figure 2(b)] in which equiaxed $\alpha$ grains dispersed in a transformed $\beta$ matrix that consists of fine scale Widmanstätten $\alpha$-platelets separated by $\beta$-laths. ${ }^{9}$ Sintering at high temperature above the $\beta$-transition temperature and subsequent slow rate cooling in the furnace under Ar atmosphere however resulted in the development of the so-called Widmanstätten microstructure in both Powder compacts [Figure $3(\mathrm{a}-\mathrm{c})$ ]. In this structure, colonies of $\beta$ lathes (bcc and rich in $\mathrm{V}$ ) and $\alpha$ platelets (hcp and rich in $\mathrm{Al}$ ) formed inside the prior $\beta$ grains [Figure 3(b)]. The percentage and thickness of $\beta$-phase were measured using five SEM micrographs taken at 1000 magnification such as shown in Figure 3(b) and an image analyzing program (Scion Image). The percentage and thickness of $\beta$-phase in Powder A compacts were found to be $18-20 \%$ and $0.2-1 \mu \mathrm{m}$, respectively. The thickness of $\alpha$-platelets varied between 4 and $8 \mu \mathrm{m}$. In Powder B compacts, however, the $\alpha$-platelets were found thicker as compared with Powder A compacts, varying between 5 and $20 \mu \mathrm{m}$ [Figure 3(c)].

The final percent porosities and mean pore sizes of the sintered powder A and B compacts are tabulated in Table I together with the applied cold compaction pressures. The mean pore size and porosity values of the compacts decrease with increasing compaction pressure as tabulated in Table I. The porosities range between 34 and $41 \%$ for Powder A and 43 and $54 \%$ for Powder B compacts. The mean pore sizes range between 80 and $98 \mu \mathrm{m}$ for Powder B and 53 and 81 $\mu \mathrm{m}$ for Powder A compacts. The polished surface optical micrographs of Powder A and B compacts with various porosities are shown in Figures 4 and 5, respectively. Larger pore sizes of Powder B compacts are also clearly seen in these figures. It was also found that the pores were completely open within the porosity range of $34-54 \%$.

Figure 6(a) shows the compressive stress-strain curves of sintered Powder A compacts (cold compaction pressure: $500 \mathrm{MPa}$ ) of $l / d$ ratios of 0.65 and 1.5 . The stress values rise to a maximum stress (compressive strength) as marked by arrows in Figure 6(a), after which the compacts fail by particle separation in the planes $45^{\circ}$ to the loading axis. Since the compression strength of powder compacts varies

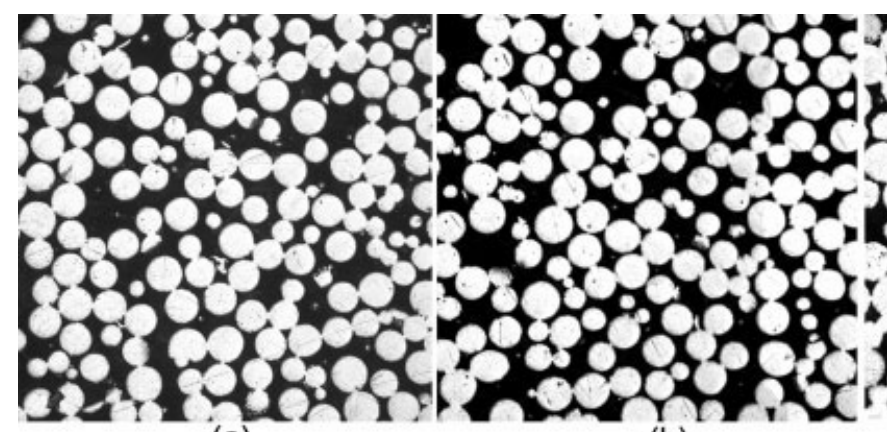

(a) (b)

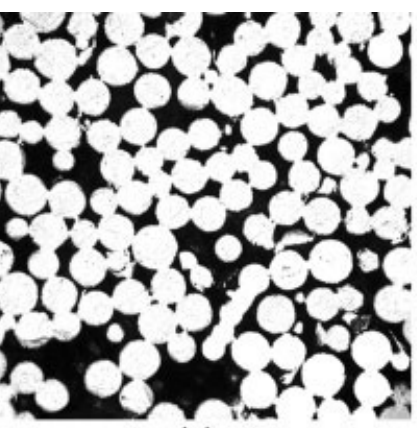

(c)

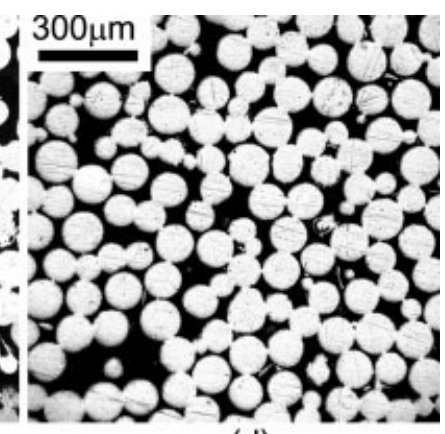

(d)

Figure 4. Optical micrographs of the polished cross-sections of powder A compacts with porosities (a) 41\% (200 MPa), (b) 40\% (300 MPa), (c) 38\% (400 MPa), and (d) 34\% (500 MPa). 


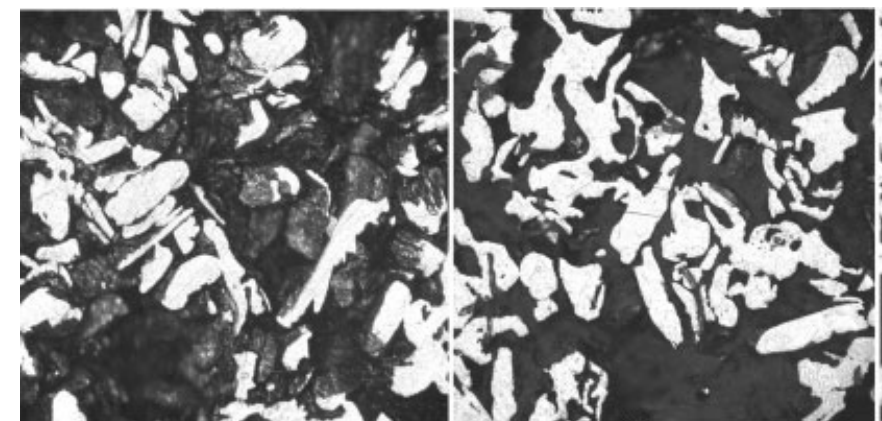

(a) (b)

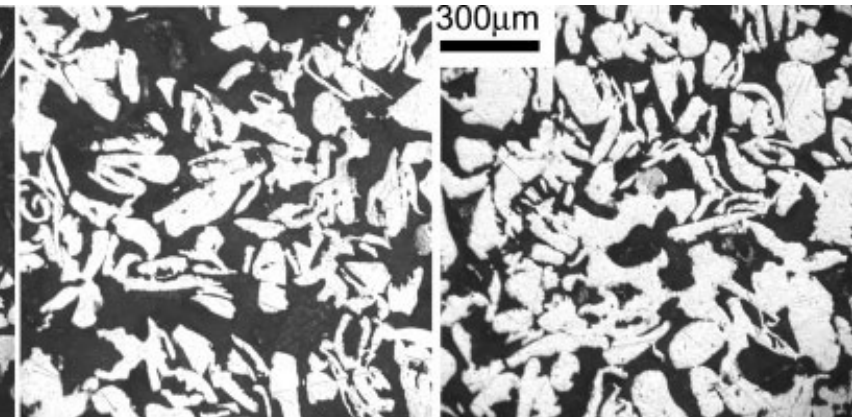

(c)

(d)

Figure 5. Optical micrographs of the polished cross-sections of Powder B compacts with porosities (a) 54\% (50 MPa), (b) 51\% (100 MPa), (c) 49\% (200 MPa), and (d) 43\% (400 MPa).

with the $l / d$ ratio, the compressive strength values are only used for the comparison of Powder A and Powder B compacts. The yield stress is however found to be independent of $l / d$ ratio for both types of powder compacts. Similar effects of $l / d$ ratio on the compression properties were also confirmed in the sintered compacts cold-compacted at lower pressures. The representative compressive stressstrain curves of sintered Powder A and B compacts cold- compacted at various pressures are shown in Figure $6(b, c)$, respectively. Powder A and B compacts show generally similar compression stress-strain behaviors. The strains corresponding to the maximum stresses in Figure $6(b, c)$ are considered as the failure strains. The elastic modulus of the compacts is determined in the initial linear region of stress-strain curves and the yield strength is taken as the proportional limit as shown in Figure 6(b,c).

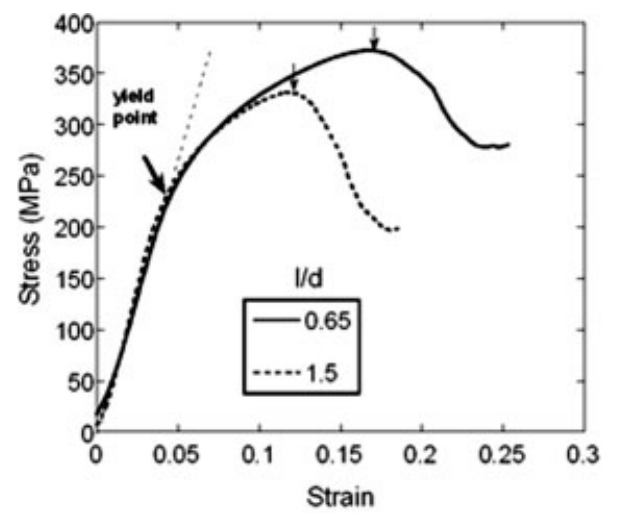

(a)

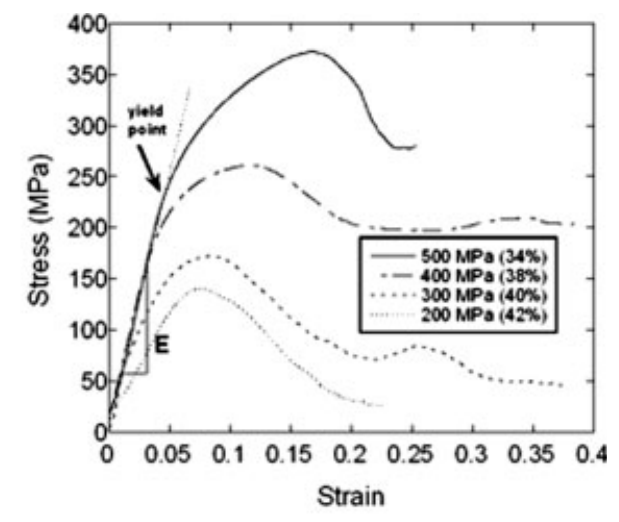

(b)

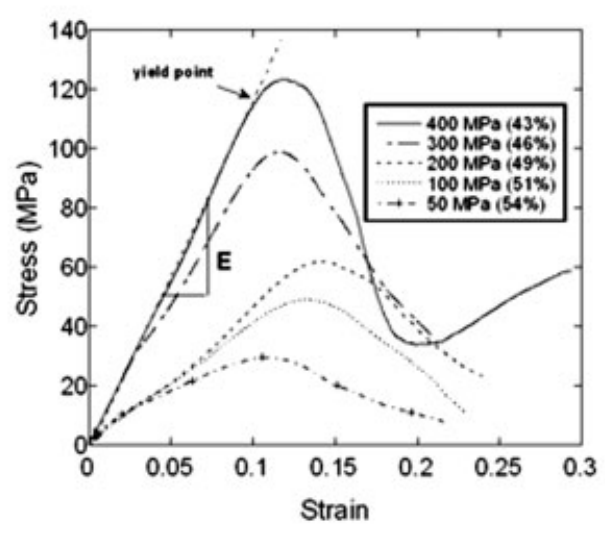

(c)

Figure 6. Compression stress-strain curves of (a) Powder A compacts of varying $/ / d$ ratios and (b) Powder A and (c) Powder B compacts $(/ / d=0.65)$. 


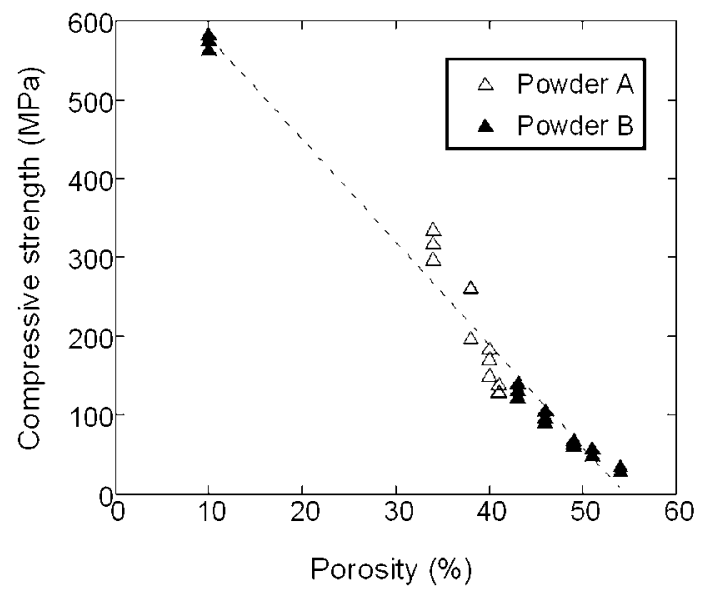

(a)

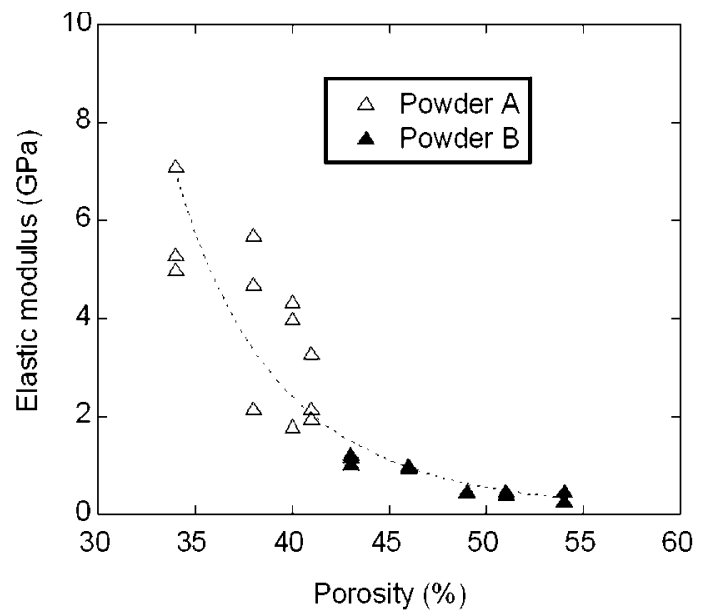

(b)

Figure 7. Variation of (a) compressive strength and (b) elastic modulus with percent porosity.

The variation of the compressive strength of compacts with percent porosity is shown in Figure 7(a). As seen in this figure, the compressive strength of Powder B compacts varies between 30 and $120 \mathrm{MPa}$ while the compressive strength of Powder A compacts varies between 120 and $350 \mathrm{MPa}$. The compressive strength of Powder B compact with $10 \%$ porosity shown in Figure 7(a) is higher than 500
MPa. The variation of the elastic modulus of compacts with porosity is shown in Figure 7(b). Similar to the compressive strength, the modulus values increase, from 0.5 to $7 \mathrm{GPa}$, with decreasing porosity, from 54 to $34 \%$.

The failure of compacts of $l / d$ ratios of 0.65 and 1.5 occurs by the separation of the particles in planes $45^{\circ}$ to the loading axis, as shown in Figure $8(\mathrm{a}, \mathrm{b})$ with arrows.
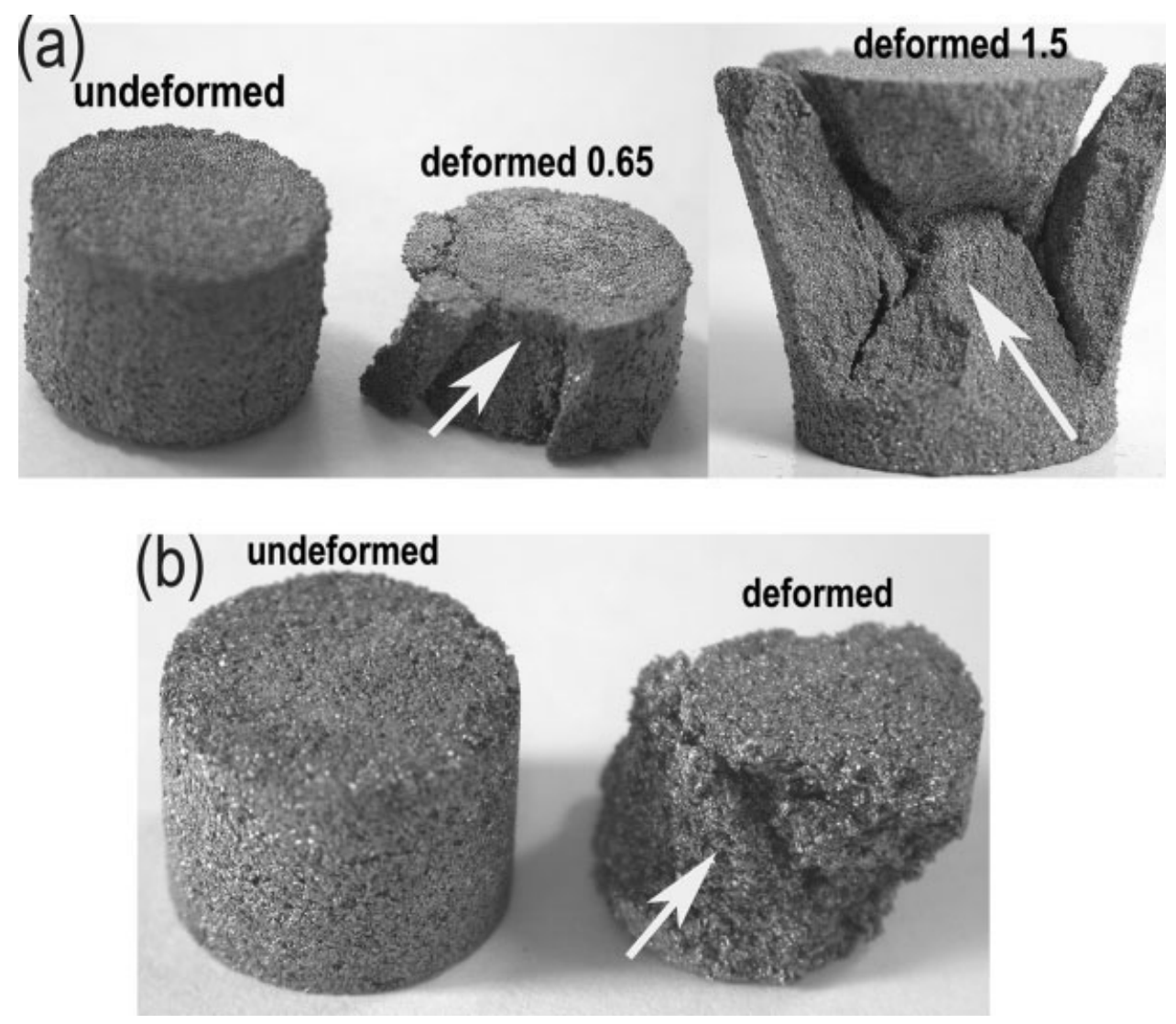

Figure 8. Undeformed and deformed pictures of (a) Powder A compacts with $34 \%$ porosity and (b) Powder B compact with $49 \%$ porosity. 


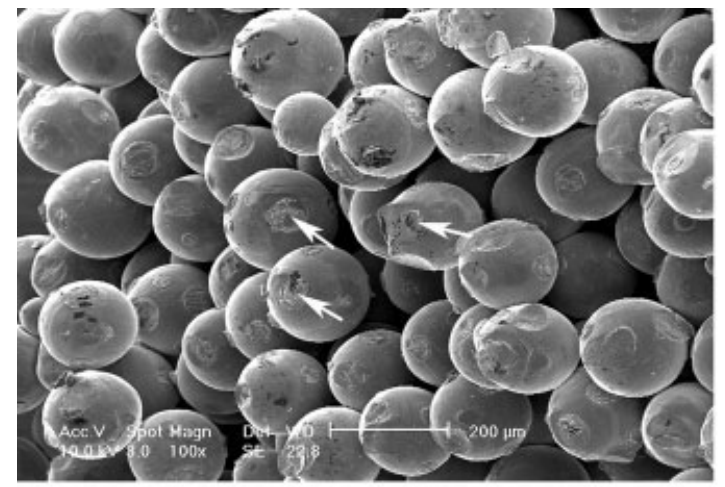

(a)

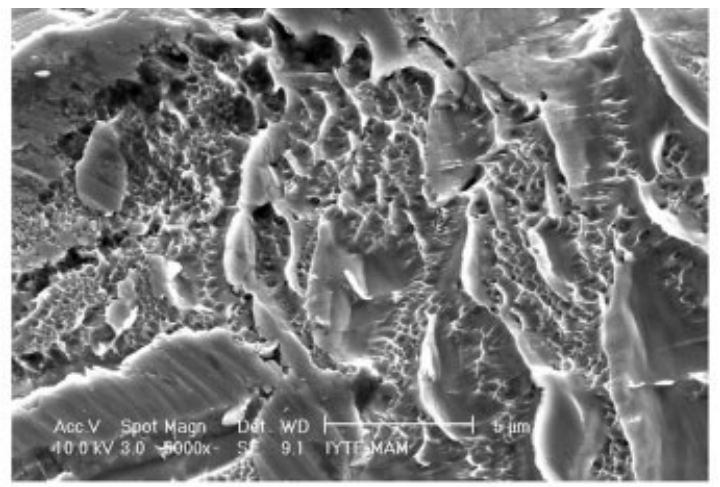

(b)

Figure 9. SEM micrographs of Powder A compacts (40\% porosity) showing (a) the fractured contacts between particles and (b) ductile failure in a contact region.

Following the separation of the planes, the compacts with higher porosities $(>49 \%)$ crushed into many small pieces. Compacts with lower porosities (34 and 38\%) however locally deformed until about large strains nearly at constant stresses [Figure 6(b)]. The failure of the samples proceeds with the separation and/or tearing of the contact zones between particles as marked with arrows in Figures 9(a) and 10(a) for Powder A and Powder B compacts, respectively. The contact zones in Powder A compacts show a relatively ductile fracture mode of composing of dimples; see Figure 9(b), while the fracture surface of contacts of Powder B compacts resembles a more granular mode of failure [Figure 10(b)].

The polished and etched cross-sections of Powder A compact samples deformed until about failure further showed that voids initiate primarily in $\alpha$-platelets and/or at $\alpha / \beta$ interface and their sizes were measured 1-2 $\mu \mathrm{m}$ before coalescence (Figure 11). Figure 12(a,b) are the AFM images of a sintered Powder A compact sample deformed until about failure. The interparticle bond separation between two particles is clearly seen in Figure 12(a).
Figure 12(b) shows that the separation proceeds along the $\alpha / \beta$ interface.

\section{DISCUSSION}

Relatively higher percent porosity levels found in Powder $\mathrm{B}$ than in Powder A compacts at the same cold compaction pressures (200-400 MPa) is due to angular particle shape, leading to the higher possibility of pore formation between the particles due to irregular shapes. The compaction pressure has also a significant effect on the final measured porosity of the compacts as seen in Table I. Increasing compaction pressure increases the relative density of green compacts by providing higher contact areas between particles. It is noted in Figure 7(a) that the compressive strengths of Powder A and B compacts with the similar porosities, 40-42\%, are very similar, probably confirming that the compressive strength of the compacts is primarily affected by the porosity, rather than the particle shape and the microstructure development. The marked differences between Powder A and Powder B compacts are however

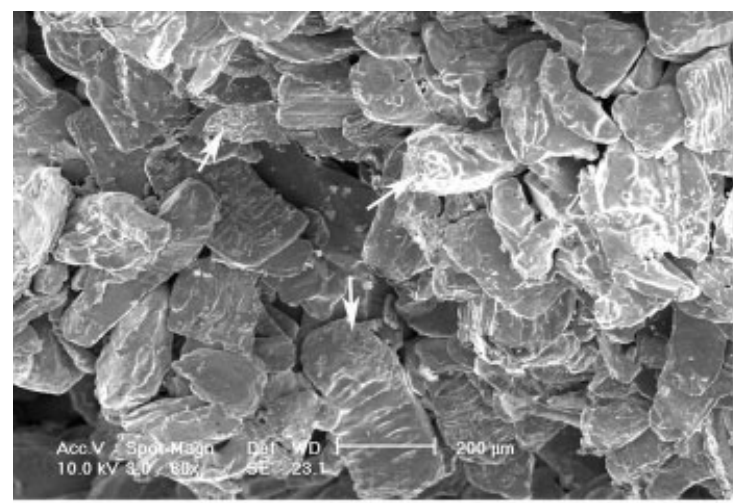

(a)

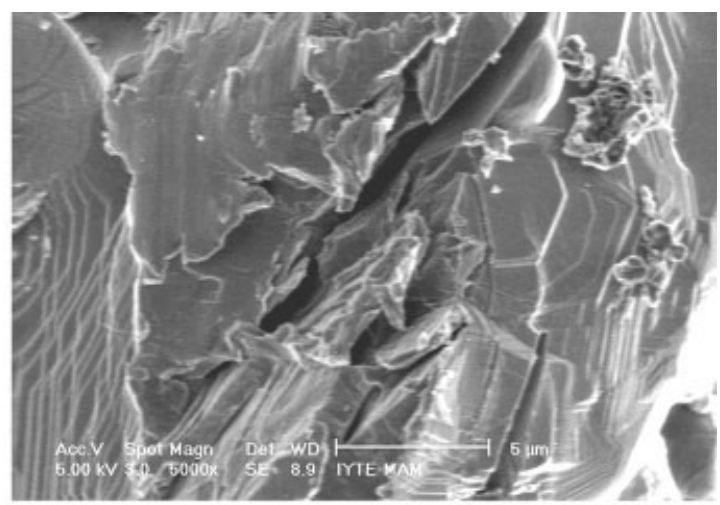

(b)

Figure 10. SEM micrographs of Powder B compacts (49\% porosity) showing (a) the fractured contacts between particles and (b) granular fracture at the contact area. 


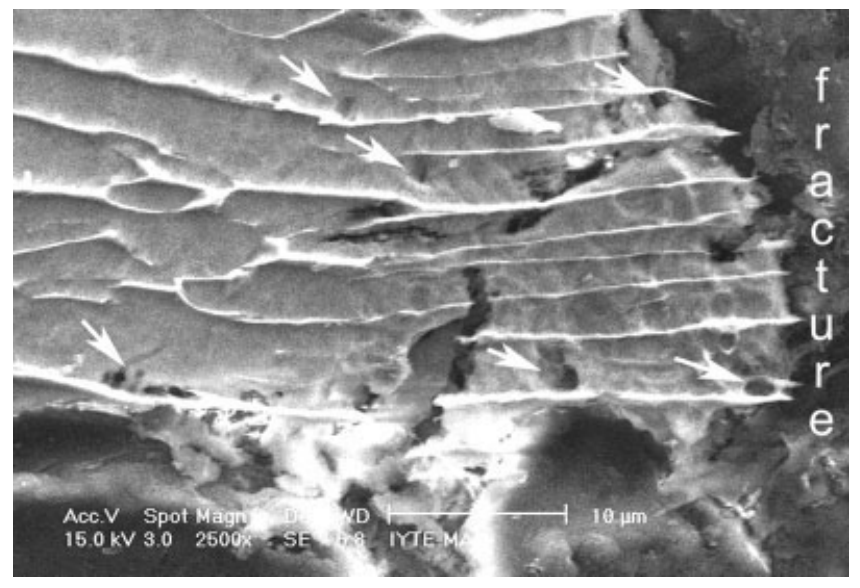

Figure 11. Voids and macrocracks in a failed Powder A compact sample (white arrows show the voids).

visible particularly for the level of attained strength and postmaximum load behaviours of the compacts. The compacts made of spherical powders [Figure 6(b)] provide higher compressive strength for a given applied strain and compaction stress used as compared with the compacts of irregularly shaped powders. Postmaximum load stage corresponds to the collapse of the pores and/or interparticle bond separation, and the compacts of Powder A provides higher deformation capacity than Powder B compacts during the process of mechanical instability.

The modulus of natural bone was reported to vary between 1 and $20 \mathrm{GPa}^{10}$ and therefore, the elastic modulus range of sintered Ti64 compacts $(0.5-7 \mathrm{GPa})$ is relatively comparable with the reported elastic modulus range of natural bone. The compressive strength of the sintered Powder B compacts of $\sim 50 \%$ porosity $(\sim 50 \mathrm{MPa})$ with $l / d$ ratio of 0.65 satisfies the strength requirement for canceleous bone replacement (3-20 MPa). ${ }^{11}$ The compressive strength of Ti foams produced by the space holder method with porosities of 52 and $43 \%$ were reported $\sim 200$ and $\sim 300 \mathrm{MPa}$, respectively. ${ }^{5}$ At similar porosities, 51 and $43 \%$, the compressive strengths of the nonstandard size sintered powder compact samples are $\sim 50$ and $\sim 120 \mathrm{MPa}$, respectively. The differences are mainly due to the differences in the deformation modes of these two different groups of materials. In metal foams, the deformation usually proceeds with cell wall buckling and/or crushing in a localized region at the plateau stress, while in the studied sintered compacts the failure occurs in planes diagonal to the loading axis by interparticle bond separation as will be explained later. The yield strength of the cortical bone was however reported to be much higher than that of canceleous bone; within the range between 104 and $121 \mathrm{MPa} .{ }^{12}$ For the studied powder compacts, the yield strengths of Powder A and Powder B compacts with the porosities of $40-42 \%$ are higher than $100 \mathrm{MPa}$ (Figure 13); therefore, satisfy the strength requirement for the cortical bone replacement. A linear interpolation to the data given in Figure 13 further gives following relation between percent porosity $(P)$ and yield strength $\left(\sigma_{\mathrm{y}}\right)$;

$$
\sigma_{\mathrm{y}}(\mathrm{MPa})=602.39-11.337 \times P
$$

For comparison purpose, the variation of $0.2 \%$ offset strength of Ti compacts (particle size: $374 \mu \mathrm{m}$ ) with porosity, which was previously reported by $\mathrm{Oh}$ et al., ${ }^{8}$ is also shown in Figure 13. As is noted in the same figure, $\mathrm{Ti}$ compacts with porosities only lower than $\sim 25 \%$ satisfy the strength requirement of human cortical bone. On the other hand, the critical porosity increases to $\sim 40 \%$ with the use of stronger Ti64 compacts.

The mean pore size of prepared compacts is smaller than the critical pore size (required for the attachment and proliferation of new bone tissue) reported by Hubert et al. ${ }^{13}$
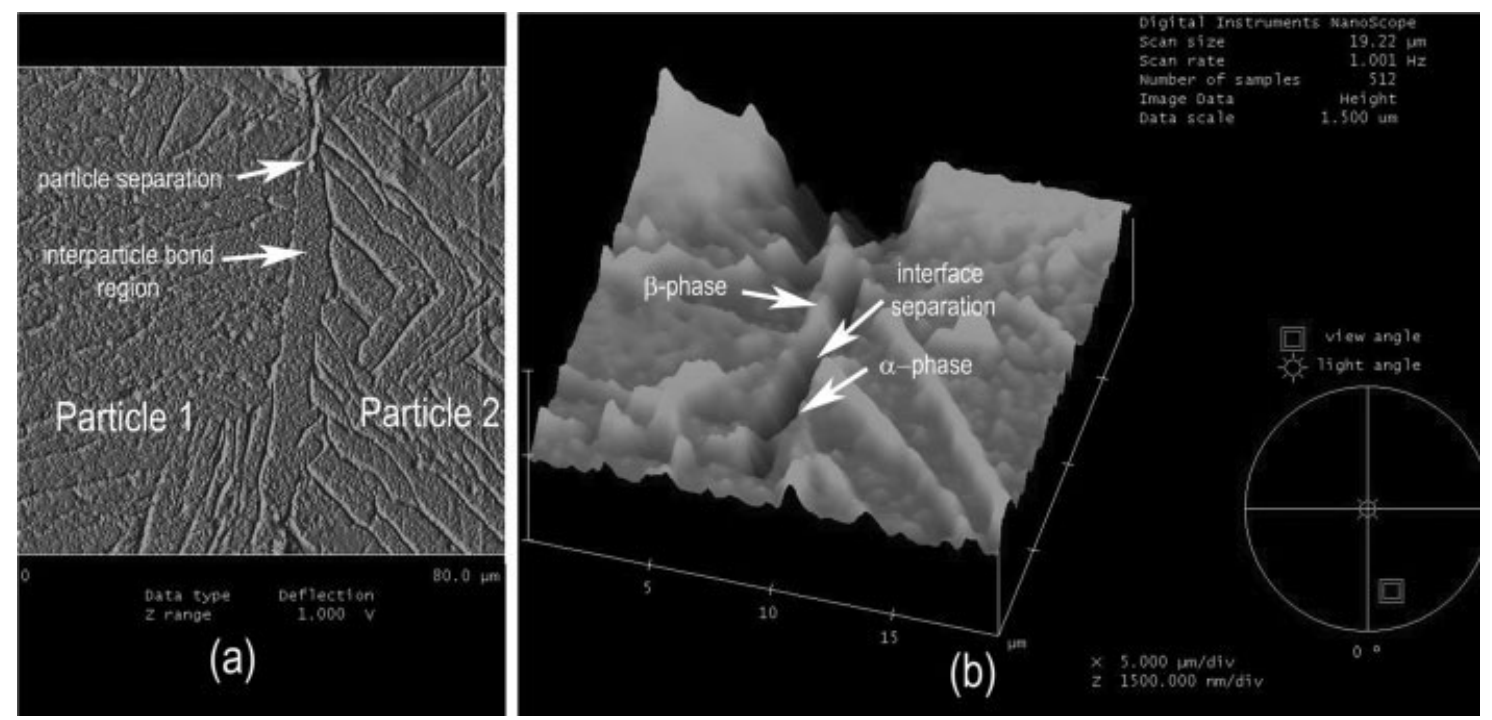

Figure 12. AFM micrographs of polished and etched deformed Powder A compact cross-section showing (a) interparticle bond region between two particles (phase image) and (b) the particle separation between $\alpha / \beta$ interface (height image). 


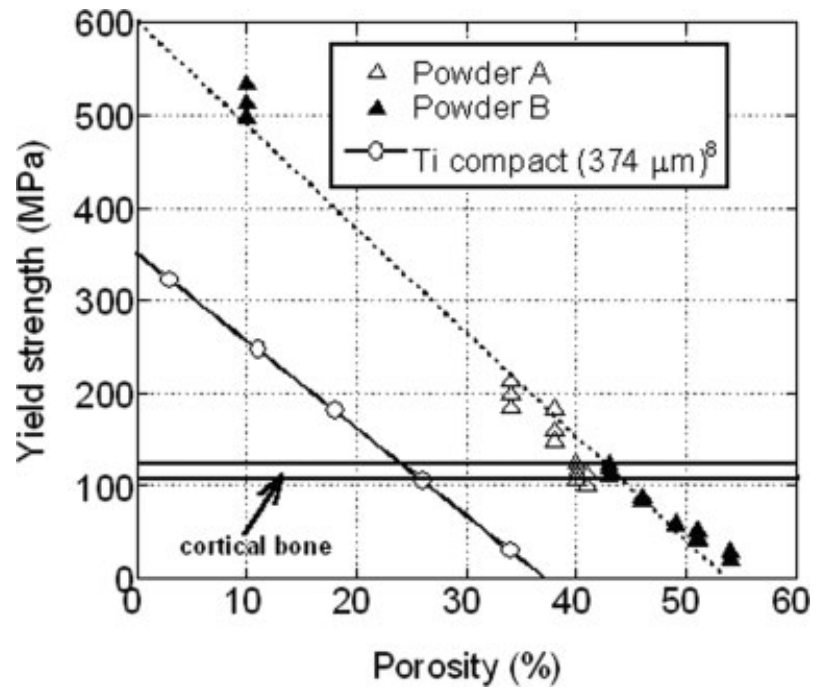

Figure 13. Variation of yield strength with percent porosity.

$(100 \mu \mathrm{m})$, while higher than the value $(50 \mu \mathrm{m})$ reported by Bobyn et al. ${ }^{14}$ Alternative ways of increasing mean pore size without significantly increasing porosity may include increasing particle size and the addition of predetermined amount and particle size of space holder such as ammonium bicarbonate. $^{3-5}$ The interrelationships between porosity and pore size and the effects of compaction pressure and the addition of space holder should be further investigated in detail for the manufacturing of implant structures with optimum pore size and porosity, which is out of scope of this study.

The granular mode of fracture in Powder B compacts may be because of the lower porosity attained and higher interstitial impurity levels in these compacts. The coalescence of the voids initiated primarily in $\alpha$-platelets and/or at $\alpha / \beta$ interface (1-2 $\mu \mathrm{m}$ ) likely lead to development of macrocracks and complete separation of interparticle bond region along the $\alpha / \beta$ interface [Figure 12(b)]. The critical strain, strain corresponding to the maximum stress at which particles separation and/ or shearing at contact points started to develop in compacts with $l / d$ ratio of 0.65 ranged between 7 and $15 \%$ [Figure $6(\mathrm{~b}, \mathrm{c})]$. It was shown previously that the critical strain level was quite different in the Widmanstätten and equiaxed microstructures of a bulk Ti64 alloy; although Widmanstätten microstructure showed strain localization at $8-10 \%$ strains, equiaxed structure did not show any localized shearing, ${ }^{15}$ confirming a strong dependency of mechanical properties on the microstructure. One of the limitations toward the use of powder compact implants may be the relatively low critical strains at which the separation of particles starts, which could be further optimized with the control of microstructure development and microstructural parameters including percentages and thicknesses of $\alpha$ - and $\beta$-phases through the heat treatment processes applied to bulk Ti64 alloy.

\section{CONCLUSIONS}

Sintered powder compacts of Ti64 alloy were prepared in the porosity range of $34-54 \%$ using atomized spherical and angular powders (100-200 $\mu \mathrm{m})$ by varying the cold compaction pressure. The final porosities of compacts were found to be the function of the applied cold compaction pressure and the powder type used. The mechanical properties, the compressive strength, elastic modulus and yield strength of compacts were determined through compression testing of cylindrical samples. The results have shown that the yield strength of the compacts having porosity level of $40-42 \%$ was comparable with that of human cortical bone. As compared with Ti powder compacts, Ti64 powder compacts also showed higher yield strength at similar porosity range. Microscopic studies of the failed samples showed that failure occurred primarily by the separation of interparticle bond regions in planes $45^{\circ}$ to the loading axis.

\section{REFERENCES}

1. Pilliar RM. Porous-surfaces metallic implants for orthopedic applications. J Biomed Mater Res 1987;21(A1 Suppl):1-33.

2. Long M, Rack HJ. Titanium alloys in total joint replacementA material science perspective. Biomaterials 1998;19:16211639.

3. Bram M, Stiller C, Buchkremer HP, Stöver D, Baur H. High purity titanium, stainless steel and superalloy parts. Adv Eng Mater 2000;2:196-199.

4. Wen CE, Mabuchi M, Yamada Y, Shimojima K, Chino Y, Asahina T. Processing of biocompatible porous $\mathrm{Ti}$ and $\mathrm{Mg}$. Script Mat 2001;45:1147-1153.

5. Wen CE, Yamada Y, Shimojima K, Chino Y, Asahina T, Mabuchi M. Processing and mechanical properties of autogenous titanium implant materials. J Mater Sci 2001;13:397-401.

6. Oh IH, Nomura N, Masahashi N, Hanada S. Mechanical properties of porous compacts prepared by powder sintering. Script Mat 2003;49:1197-1202.

7. ASTM F 1580-95. Standard specification for titanium and Ti6Al4V alloy powders for coating surgical implants. West Conshohocken: American Society for Testing and Materials.

8. Oh IH, Nomura N, Masahashi N, Hanada S. Microstructures and mechanical properties of porous titanium compacts prepared by powder sintering. JIM Mater Trans 2002;43:443-446.

9. American Society for Metals. Metals Handbook, 9th ed, Vol. 4. Metals Park, OH: American Society for Metals; 1990. pp 763-774.

10. Rho JY, Spearing LK, Zioupos P. Mechanical properties and the hierarchical structure of bone. Med Eng Phys 1998;20:92-102.

11. Tencer AF, Johnson KD. Factors affecting the strength of bone. In: Biomechanics in Orthopaedic Trauma: Bone Fracture and Fixation. London: Martin Dunitz; 1994. pp 954-962.

12. Burstein AH, Reilly DT, Martens M. Aging of bone tissue: Mechanical properties. J Bone Joint Surg A 1976;58:82-86.

13. Hulbert SF, Young FA, Mathews RS, Klawitter JJ, Talbert CD, Stelling FH. Potential of ceramic materials as permanently implantable skeletal prostheses. J Biomed Mater Res 1970;4: 433-456.

14. Bobyn JD, Pilliar RM, Cameron HU, Weatherly GC. The optimum pore size for the fixation of porous surfaced metal implants by ingrowth of bone. Clin Orthop Relat Res 1980;150:263-270.

15. Silva MG, Ramesh KT. The rate-dependent deformation and localization of fully dense and porous Ti-6Al-4V. Mater Sci Eng A 1997;232:11-22. 